\title{
Construção de um dicionário virtual para incremento do aprendizado de Biologia no ensino propedêutico
}

\author{
Creation of a virtual dictionary for increase of the learning of Biology in the introduc- \\ tory teaching
}

\author{
Iana Ciara Santos de Albuquerque \\ Instituto Federal do Rio Grande do \\ Norte. Campus Natal/Zona Norte. \\ CEP: 59112-490. Natal, RN. \\ iana.albuquerque7@gmail.com
}

\section{Jéssica Fernanda Ramos Coelho Instituto Federal do Rio Grande do Norte. Campus Natal/Zona Norte. CEP: 59112-490. Natal, RN. jess.fernand@hotmail.com}

\author{
João Pedro Lobo Antunes \\ Instituto Federal do Rio Grande do \\ Norte. Campus Natal/Zona Norte. \\ CEP: 59112-490. Natal, RN. \\ pedro7lobo@gmail.com
}

\author{
Cínthia Diniz do Nascimento \\ Instituto Federal do Rio Grande do \\ Norte. Campus Natal/Zona Norte. \\ CEP: 59112-490. Natal, RN. \\ cinthiadiniz97@hotmail.com \\ Darlla Layse Torres de Lima \\ Instituto Federal do Rio Grande do \\ Norte. Campus Natal/Zona Norte. \\ CEP: 59112-490. Natal, RN. \\ darlla_trs@hotmail.com \\ Rodolfo da Silva Costa \\ Instituto Federal do Rio Grande do \\ Norte. Campus Natal/Zona Norte. \\ CEP: 59112-490. Natal, RN. \\ rodolfo.costa@ifrn.edu.br
}

\author{
Neyvan Renato Rodrigues da Silva \\ Instituto Federal do Rio Grande do \\ Norte. Campus Natal/Central. \\ CEP: 59015-000. Natal, RN. \\ neyvan.rodrigues@ifrn.edu.br
}

\begin{abstract}
Resumo Este trabalho visa analisar a acuidade do uso de um Dicionário Virtual Biológico, Etimológico e Circunstanciado no processo de ensino-aprendizagem da biologia, na esfera do ensino propedêutico. O Dicionário Virtual de Biologia - o qual porta cerca de dois mil e trinta e um verbetes referentes ao conteúdo de biologia do primeiro ao terceiro anos do ensino médio - é um recurso de aprendizagem destinado a alunos do ensino médio e está estruturado em wiki (modelo específico de software para a criação de documentos em hipertexto); apresenta uma definição, etimologia, hiperlinks e ilustrações para cada verbete. Por fim, essa proposta corrobora com uma maneira contemporânea de estimular os alunos, propondo o modelo online e interativo, de acesso livre e irrestrito através da internet, enquanto o padrão tradicional está voltado para a publicação impressa, o qual se encontra obsoleto. Espera-se que ao fim do ano de 2015 o dicionário, além da versão tradicional para web - em formato de site - possua também uma outra, para smartphones Android, a qual encontra-se em processo de construção.
\end{abstract}

Palavras-Chave: aprendizado, biologia, conceitos, dicionário virtual.

\begin{abstract}
This work aims to analyze the impact of the use of a Virtual Etymologic Biological and Detailed Dictionary in the introductory process of teaching and learning biology. The Virtual Biologic Dictionary - which have about two thousand and thirty-one entries relating to the content of biology from first to third year high school - is a learning resource for high school students. The Dictionary, structured in wiki (specific type of software to creation of a hypertext document), has a definition, etymology, hiperlinks and illustrations for each entry. Finally, this proposal confirms a contemporary way to stimulate students, proposing the free model and unrestricted access over the internet, while the traditional pattern is facing the print publication, which is obsolete. It is
\end{abstract}


expected that by the end of 2015 the dictionary, besides the traditional version for web - in site format - also own another for Android smartphones, which is still in construction.

Keywords: learning, biology, concepts, virtual dictionary. 


\section{Introdução}

Desde o início da escolaridade, a utilização do dicionário se configura num eficaz recurso metodológico, pois ao portar milhares de conceitos consiste numa ferramenta didático-pedagógica capaz de expandir as fronteiras intelectuais do discente. De acordo com Duarte [11] os benefícios de seu uso vão além dos aspectos semânticos, como por exemplo, o aprimoramento do vocabulário.

Para Barbosa [3] as vantagens da utilização do dicionário são evidentes:

“...permite o acesso imediato ao conjunto da terminologia em uso, torna mais fácil a ulterior introdução dos suplementos de informação que os progressos das pesquisas não deixarão de carrear, e, sobretudo, legitima a colocação lado a lado de segmentos metalinguísticos cujo grau de elaboração e de formulação é bastante desigual, justapondo definições rigorosas, exposições incompletas e indicações de domínios problemáticos, ainda inexplorados."

O descobrimento de estratégias adequadas para resolução das dúvidas que se apresentam é suposto pelo uso de dicionários, além da aquisição da consciência da necessidade de um uso responsável da língua. Tal processo se baseia, fundamentalmente e de maneira inequívoca, na aquisição e no uso léxico, através do qual se forma a língua e toda a sua estrutura, dizendo respeito aos aspectos gramaticais e sintáticos [26].

Duarte [11] chega a adjetivar o dicionário como um "inestimável recurso metodológico", haja visto a sua gama de aplicabilidade, bem como a confiança que se pode atribuir às definições que esse contém, observando ainda o histórico desse instrumento que o fez tornar-se tão imprescindível ao processo de ensino-aprendizagem.

Acredita-se que o primeiro dicionário tenha surgido na Mesopotâmia, por volta do ano 2.600 a.C. - em escrita cuneiforme ${ }^{1}$ e que, na verdade, apenas listava termos necessários ao cotidiano da época, por exemplo, repertórios de signos, nomes de profissões, divindades e objetos usuais; funcionando como dicionários unilíngues. Já a organização de dicionários que traziam os significados e usos das palavras foi iniciada, apenas, por volta do século I pelos gregos para catalogar o uso das palavras de sua língua, o grego. Por mais que esses dicionários limitassem-se as definições de termos linguísticos ou literários e não fossem organizados em ordem alfabética, os gregos e os romanos

1 Diz-se do uma das mais antigas escritas mundo, criada pelo povo Persa; possui essa denominação devido a sua produção ser realizada com o auxílio de objetos em formato de cunha [10]. já os utilizavam para esclarecimentos de dúvidas de termos e conceitos [20].

Com o fim da Idade Média houve o surgimento de dicionários e glossários organizados alfabeticamente, que se deu através dos monges, quando as glosas desses manuscritos latinos tornaram-se numerosas, para facilitar sua localização. Após isso, uma sucessão de outros acontecimentos consequentes das necessidades do homem em se comunicar - como uma primeira tentativa de dicionário bilíngue latim-vernáculo - ocorreram, corroborando com a incorporação do estilo de dicionário que usamos atualmente, ocorrendo durante o renascimento, com o objetivo de traduzir as línguas clássicas para as modernas em função da bíblia. Com o advento da imprensa, no século XV, alavancou-se a difusão e o uso de novos dicionários [20].

De acordo com Instituto de Estudos Brasileiros, da Universidade de São Paulo (USP) o mais antigo dicionário de língua portuguesa - Vocabulario Portuguez e Latino foi escrito pelo padre inglês Raphael Bluteau (1638-1734) e publicado em 1712. Esse fato mostra o quão antiga é essa metodologia de ensino e como os teóricos já estavam engajados desde os primórdios em esclarecer aspectos referentes ao contexto léxico da língua, ou seja, a compilação de palavras de uma língua com vocabulário próprio desse idioma, bem como verbetes adjacentes.

Segundo Sousa [24] em 1789, ganha destaque o Dicionário da Língua Portuguesa de Antônio Moraes Silva, publicado em Lisboa - nesse período fora considerado o melhor e mais completo dicionário da Língua Portuguesa, o qual em 1813 foi enriquecido com a adição de novos verbetes. Atualmente, no Brasil, ganham notoriedade no campo lexicográfico os seguintes autores: Francisco Caldas Aulete, Carolina Michaelis de Vasconcelos e Aurélio Buarque de Holanda Ferreira. Nesse sentido, temos a ênfase na obra de Buarque de Holanda que é autor do Dicionário Aurélio da Língua Portuguesa, considerado o mais popular dicionário da língua portuguesa, obra de destaque nos cenários nacional e internacional, o qual continha cerca de 150 mil vocábulos quando foi publicada a sua primeira versão na década de 80 .

Nesse contexto, foi lançada em 2001, no Rio de Janeiro, pelo Instituto Antônio Houaiss, a primeira edição do Grande dicionário Houaiss da língua portuguesa, elaborado pelo lexicógrafo brasileiro Antônio Houaiss. O projeto de confecção do dicionário começou em 1985, onde Antônio Houaiss tinha a ambição de criar o mais completo dicionário de língua portuguesa já compilado. Desta forma, dezesseis anos depois foi concebida a obra máxima de referência da língua portuguesa, segundo a Editora Objetiva, - o dicionário Houaiss - desenvolvida por uma 
equipe formada por mais de 150 especialistas - lexicógrafos, redatores, etimólogos, professores, datadores, revisores. O padrão de excelência da pesquisa e o rigor na realização da obra, em todas as suas etapas, consagram, atualmente, o dicionário Houaiss como o mais completo e moderno dicionário da língua portuguesa [4].

O Dicionário Houaiss traz cerca de 228.500 verbetes, 376.500 acepções, 415.500 sinônimos, 26.400 antônimos e 57.000 palavras arcaicas. Além da quantidade de verbetes, a equipe de edição pesquisou também as etimologias de cada palavra e o seu primeiro registro no idioma português. O vocabulário do Dicionário Houaiss abrange a terminologia atual do setor tecnológico e científico, assim como nomenclaturas atualizadas no campo da zoologia, botânica e anatomia, e ainda expressões populares e termos específicos do português europeu, brasileiro, africano e asiático [5].

É sabido que, apesar dos autores se preocuparem com o aspecto lexical, a maioria do leitor público faz uso do livro apenas para a descodificação do texto lido; atualmente, porém, o dicionário assume um papel diferente nas metodologias de ensino, se tornando imprescindível para a aprendizagem do léxico e da língua em geral [26].

Com o decorrer do tempo, novos modelos de dicionários surgiram, tais como: Dicionários de sinônimos e antônimos, de abreviaturas, bilíngues ou plurilíngues. E acoplado a isso surgiu também o conceito de dicionário temático, os quais organizam vocabulários específicos de determinada ciência, arte ou atividade técnica, tais como: Dicionário de Comunicação, Dicionário Jurídico, Dicionário de Astronomia, Dicionário de História, Dicionários de Astronáutica e de Biologia [19].

Os vocábulos elencados nesse poderoso instrumento didático - o dicionário temático - estabelecem relações semânticas entre si. Essas relações, por sua vez, se caracterizam por estabelecerem semelhanças entre os verbetes pertencentes a um mesmo campo temático, de forma que sua significação relacionar-se-á a outra terminologia, estabelecendo um vínculo de interdependência entre os termos [21].

Rangel e Bagno [21] expõem que os dicionários vêm organizados em acervos diferentes, dirigidos a alunos de níveis distintos de ensino-aprendizagem, e citam que

“..por isso mesmo, sem esquecer o que é comum a todo e qualquer dicionário escolar de Língua Portuguesa, perseguem objetivos específicos, ou seja, obedecem a propostas pedagógicas e lexicográficas particulares, voltadas para o aluno de um ou outro desses níveis. Assim, têm características próprias: diferem na quantidade e no tipo de palavras que registram, bem como na forma de explicar os seus sentidos e de montar o dicionário com vistas a facilitar o manejo pelo aluno."

Gomes [13] reforça o afirmado por Rangel e Bagno [21], quando diz que se começa a delinear critérios e paradigmas para a construção de propostas lexicográficas adequadas ao público e à realidade brasileira, oferecendo como produto final dicionários, de fato, escolares e não meros recortes de obras mais amplas da língua portuguesa. Assim, os autores acima se articulam de forma a deixar claro que atualmente não mais se formulam dicionários que apresentam única e diretamente o significado do termo, e sim se vislumbra adequar a proposta ao públicoalvo, aproximando-a da realidade vivenciada por esse grupo social.

Em suas diversas roupagens, os dicionários, que outrora se prendiam à métrica, passaram a adotar formatos mais arbitrários, de forma que, como já foi dito, a categoria de dicionários temáticos passou a existir. Dentro desse contexto ressalta-se a existência de dicionários que trazem conceitos importantes e referentes à sua área específica, tal qual como ocorre em dicionários de biologia, história e geografia. Segundo Duarte [11] "esse instrumento acompanhará os educandos jornada afora, não somente nas aulas de Língua Portuguesa, mas também nas demais disciplinas".

Nesse sentido Barbosa [3] definiu que

“...o dicionário terminológico, ou o vocabulário técnico-científico e especializado tem um papel relevante a desempenhar no processo de ensino/aprendizagem das metalinguagens técnico-científicas, como também das linguagens especializadas, desde que sejam elaboradas de maneira a atender a certas exigências que assegurem a sua eficácia."

É notório que, apesar dos dicionários terem fugido ao seu modelo original, o seu papel na área educacional ainda os caracteriza como ferramentas didático pedagógicas de suma importância, a exemplo do supracitado por Barbosa [3], visto que as metalinguagens técnico-científicas são essencialmente incorporadas aos sistemas de ensino contemporâneos.

Nesse contexto, temos a publicação do dicionário de Biologia de José Luís Soares - que ocorreu na década de 90, que apresenta a definição de cerca de seis mil termos biológicos; apresentando na sua estrutura tabelas com dados importantes e personalidades notáveis da Biologia, constituindo-se assim como uma obra de referência na área. 
O Dicionário Etimológico e Circunstanciado de Biologia de José Luís Soares é o resultado de uma intensa pesquisa na bibliografia biológica de quatro décadas de conhecimento; objetivando facilitar o trabalho daqueles que lidam com a matéria. Porém, a obra data do ano de 1993 e encontra-se desatualizada, visto que em mais de vinte anos os avanços na área das ciências biológicas são consideráveis, além do surgimento e reformulação de algumas terminologias tornam-se naturais durante esse processo.

Além do dicionário de Biologia de José Luís Soares existem outras obras que seguem essa linha. A exemplo pode-se citar o Dicionário Básico de Biologia de Octacilio Lessa [15], e o Henderson's Dictionary of Biological Terms de Eleanor Lawrence [14], os quais também serviram de referência para a elaboração deste trabalho.

Eventos promovidos pela Academia Brasileira de Ciências (ABC), por exemplo a Conferência "Avanços e Perspectivas da Ciência no Brasil, América Latina e Caribe", expõe progressos do conhecimento em todas as áreas da ciência, e é comum que nesse tipo de acontecimento - que cada vez mais ocorre em menores intervalos de tempo - surjam informações que necessitam ser incorporadas ao cotidiano, implicando na necessidade da aquisição de um vocabulário adequado e mais rebuscado para a efetivação de tal processo.

Associada a essa questão, temos o estudo sistemático do contexto que envolve a inserção do estudante no ensino médio, observando-se que tal período é marcado por sua exposição a uma extensa gama de informações científicobiológicas, configurando-se assim na necessidade de compreensão desses conteúdos e conceitos da biologia - bem como já observara o próprio José Luís Soares. Por isso, quando os alunos entram em contato com um novo e vasto campo lexical - ressaltando os termos empregados na disciplina supracitada - estes deverão compreender o conceito e incorporá-lo ao seu vocabulário cognitivo, havendo a possibilidade da incompreensão dessas terminologias pelo estudante, o que certamente acarretará num déficit da aprendizagem.

Assim, um recurso que pode ser utilizado contemporaneamente para trabalhar esse déficit de aprendizagem dos estudantes é o uso de novas formas de aprendizagem que despertem o interesse do aluno, vinculadas a ideia do desenvolvimento do dicionário técnico. Realizando-se, assim, a junção entre simplificação do conteúdo, que muitas vezes compromete a aprendizagem pela omissão de informações, e a internet, um recurso já muito explorado pelo público para difusão das informações cotidianas, o qual traz meios dinâmicos para se trabalhar conteúdos e a praticidade de se localizar informações [1].

Analisando-se a escassez do quadro educacional atual dessas ferramentas, atrelado ao potencial das mídias soci- ais, propõe-se o uso de um dicionário etimológico e circunstanciado de biologia online, que objetiva auxiliar o discente a adquirir a significação de um termo biológico para incremento no processo ensino-aprendizagem da disciplina.

A ideia de construção de um dicionário de biologia online e interativo, no qual os conceitos são apresentados de forma simples, circunstanciada e organizada de forma didática, faz com que os discentes tenham acesso a informações pertinentes a construção do conhecimento, possibilitando uma maior amplitude da compreensão dos conceitos e significação. Além de promover a possibilidade da representação de fenômenos biológicos por animações, figuras, gráficos e esquemas didáticos que visem explicitar e circunstanciar o conceito biológico vigente no dicionário virtual, o BioWiki.

\section{Percursos metodológicos}

O desenvolvimento dessa proposta foi subdividido em três etapas: a primeira envolveu a enumeração de vocábulos do primeiro, segundo e terceiro anos do ensino médio; a segunda consiste na conceituação (etimologia e circunstância) dos verbetes elencados baseado nos livros didáticos e dicionários impressos especializados na área de Biologia, disponíveis na biblioteca do Instituto Federal de Educação, Ciência e Tecnologia do Rio Grande do Norte - Campus Natal Zona Norte (IFRN) e a terceira etapa finaliza-se com o desenvolvimento da página virtual e, a posteriori, a criação de um aplicativo do dicionário para smartphones Android.

Os livros didáticos utilizados na determinação dos vocábulos para construção do dicionário virtual envolveram as obras dos seguintes autores: Sônia Lopes [16], César e Sezar [22], Amabis e Martho [2], Armênio Uzunian [25] e Sídio Machado [17]. Além dos dicionários de José Luís Soares [23], Octacilio Lessa [15] e Eleanor Lawrence [14].

Inicialmente, o desafio consistiu-se na determinação dos verbetes em seus respectivos assuntos, partindo-se do fato de que muitos deles estão imersos em diversos conteúdos. Por exemplo, o conceito de célula é importante à Citologia tanto quanto ao campo Origem da Vida. Como solução a esta problemática, utilizou-se o recurso de hiperlinks ${ }^{2}$ nas definições dos verbetes para, assim, evitar redundância.

Dessa maneira, para a seleção dos verbetes constituintes do dicionário, verificou-se o seu uso e relevância dentro de cada grande área trabalhada. Assim, de acordo com a frequência que aquele verbete era citado, bem como a importância de seu entendimento para a construção do conteúdo como um todo, foi criada uma listagem e esses verbetes basais de biologia foram tabelados (Tabela 1). 


\begin{tabular}{|c|c|c|c|}
\hline Conteúdo & Anos & Exemplos & $\begin{array}{c}\text { Quantidade } \\
\text { de Verbe- } \\
\text { tes }\end{array}$ \\
\hline $\begin{array}{l}\text { Origem da } \\
\text { vida }\end{array}$ & $\begin{array}{l}\text { Primeiro } \\
\left(1^{\circ}\right) \text { ano }\end{array}$ & $\begin{array}{l}\text { Abiogênico; } \\
\text { Abiótico; } \\
{[\ldots . \text { Vida. }}\end{array}$ & 284 \\
\hline $\begin{array}{l}\text { Bioquí- } \\
\text { mica ce- } \\
\text { lular }\end{array}$ & $\begin{array}{l}\text { Primeiro } \\
\left(1^{\circ}\right) \text { ano }\end{array}$ & $\begin{array}{l}\text { Aceptor de } \\
\text { hidrogênio; } \\
\text { AcetilCoA; } \\
\text { [...] Ura- } \\
\text { cila. }\end{array}$ & 73 \\
\hline Citologia & $\begin{array}{l}\text { Primeiro } \\
\left(1^{\circ}\right) \text { ano }\end{array}$ & $\begin{array}{l}\text { Aberração } \\
\text { cromossô- } \\
\text { mica; } \\
\text { Acrocên- } \\
\text { trico; } \\
\text { [....] Zigó- } \\
\text { teno. }\end{array}$ & 302 \\
\hline $\begin{array}{l}\text { Embriolo- } \\
\text { gia }\end{array}$ & $\begin{array}{l}\text { Primeiro } \\
\left(1^{\circ}\right) \text { ano }\end{array}$ & $\begin{array}{l}\text { Acrossomo; } \\
\text { Alantóide; } \\
\text { g...] Zi- } \\
\text { goto. }\end{array}$ & 149 \\
\hline $\begin{array}{l}\text { Histolo- } \\
\text { gia }\end{array}$ & $\begin{array}{l}\text { Primeiro } \\
\left(1^{\circ}\right) \text { ano }\end{array}$ & $\begin{array}{l}\text { Actina; } \\
\text { Adipócito; } \\
{[. . .] \text { Zona }} \\
\text { de oclusão. }\end{array}$ & 268 \\
\hline $\begin{array}{l}\text { Classifi- } \\
\text { cação Bi- } \\
\text { ológica }\end{array}$ & $\begin{array}{l}\text { Segundo } \\
\left(2^{\circ}\right) \text { ano }\end{array}$ & $\begin{array}{l}\text { Anagênese; } \\
\text { Apomorfia; } \\
\text { [...] Taxo- } \\
\text { nomia. }\end{array}$ & 27 \\
\hline $\begin{array}{l}\text { Zoologia } \\
\text { (Filos) }\end{array}$ & $\begin{array}{l}\text { Segundo } \\
\left(2^{\circ}\right) \text { ano }\end{array}$ & $\begin{array}{l}\text { Filo Pori- } \\
\text { fera; Filo } \\
\text { Cnidaria; } \\
\text { [...] Filo } \\
\text { Chordata. }\end{array}$ & 9 \\
\hline $\begin{array}{l}\text { Seres Vi- } \\
\text { vos }\end{array}$ & $\begin{array}{l}\text { Segundo } \\
\left(2^{\circ}\right) \text { ano }\end{array}$ & $\begin{array}{l}\text { Bactéria; } \\
\text { Protozoá- } \\
\text { rio; [...] } \\
\text { Zygomicota, } \\
\text { filo. }\end{array}$ & 113 \\
\hline Botânica & $\begin{array}{l}\text { Segundo } \\
\left(2^{\circ}\right) \text { ano }\end{array}$ & $\begin{array}{l}\text { Aclamídea; } \\
\text { Albume; } \\
{[\ldots . \text { Xi- }} \\
\text { lema. }\end{array}$ & 207 \\
\hline $\begin{array}{l}\text { Programas } \\
\text { de saúde }\end{array}$ & $\begin{array}{l}\text { Segundo } \\
\left(2^{\circ}\right) \text { ano }\end{array}$ & $\begin{array}{l}\text { Acne; Afec- } \\
\text { Ção; [...] } \\
\text { Varíla }\end{array}$ & 89 \\
\hline $\begin{array}{l}\text { Fisiolo- } \\
\text { gia ani- } \\
\text { mal }\end{array}$ & $\begin{array}{l}\text { Segundo } \\
\left(2^{\circ}\right) \text { ano }\end{array}$ & $\begin{array}{l}\text { Abomasso; } \\
\text { Acelomado; } \\
\text { [...] Ver- } \\
\text { tebrado. }\end{array}$ & 119 \\
\hline $\begin{array}{l}\text { Fisiolo- } \\
\text { gia hu- } \\
\text { mana }\end{array}$ & $\begin{array}{l}\text { Segundo } \\
\left(2^{\circ}\right) \text { ano }\end{array}$ & $\begin{array}{l}\text { ADH; Aldos- } \\
\text { terona; } \\
{[\ldots] \text { Vias }} \\
\text { respirató- } \\
\text { rias }\end{array}$ & 113 \\
\hline Ecologia & $\begin{array}{l}\text { Terceiro } \\
\left(3^{\circ}\right) \text { ano }\end{array}$ & $\begin{array}{l}\text { Biosfera, } \\
\text { biótopo }\end{array}$ & 97 \\
\hline
\end{tabular}

\begin{tabular}{l|l|l|l} 
& & $\begin{array}{l}{[\ldots], \text { Ne- }} \\
\text { crofilia. }\end{array}$ & 104 \\
\hline Genética & $\begin{array}{l}\text { Terceiro } \\
\left(3^{\circ}\right) \text { ano }\end{array}$ & $\begin{array}{l}\text { Hereditari- } \\
\text { edade, Gene } \\
{[\ldots]} \\
\text { Transgê- } \\
\text { nico. }\end{array}$ & $\mid$ \\
\hline Evolução & $\begin{array}{l}\text { Terceiro } \\
\left(3^{\circ}\right) \text { ano }\end{array}$ & $\begin{array}{l}\text { Biodiversi- } \\
\text { dade, Evo- } \\
\text { lução [... }] \\
\text { Especiação. }\end{array}$ & 67 \\
\hline Total & - & - & 2031
\end{tabular}

Tabela 1: Quantitativo dos termos elencados para o dicionário virtual por conteúdo dos primeiro, segundo e terceiro anos.

Posteriormente ao processo de seleção dos verbetes de acordo com sua relevância para o estudo do conteúdo na disciplina de Biologia, foi realizada a conceituação desses termos a partir do que cada autor dos livros didáticos utilizados descrevia para defini-lo. De modo que, procuravase verificar obra por obra e manter tudo aquilo que os autores apresentavam em comum sobre aquele termo, simplificando a escrita para promover uma melhor compreensão por parte do aluno, destacando também a sua etimologia - obtida, principalmente, por meio do Dicionário de Biologia de José Luís Soares - e as circunstâncias de uso de cada termo.

Destaca-se aqui, que antes de realizar-se a postagem dos verbetes no site, para cada conceito, foi feita a releitura e proposta a avaliação dos professores de biologia de todos os 21 Campi do IFRN, para atestar a acurácia do conteúdo apresentado no site. Nesse sentido, o conteúdo dos verbetes seguiram adaptações na conceituação, seguindo um aprimoramento do que vinha sendo abordado dos conceitos nas obras referenciadas.

Como o conteúdo do site não pode ser diretamente modificado pelo público, para garantir que os conceitos se remetam de fato à sua significação, mudanças pontuais e sugestões dos leitores são recebidas através do e-mail "biowiki.ifrn@gmail.com”disponibilizado no site e, caso sejam plausíveis, são avaliadas pela equipe gestora - em relação ao conteúdo, as mudanças são avaliadas por professores de Biologia - podendo vir a ser realizadas.

Já em relação à página web na qual o dicionário está disponível, coloca-se que essa foi desenvolvida através do DokuWiki (http://www.dokuwiki.org/dokuwiki), uma ferramenta simples destinada a criação de sites. Ele oferece uma gama de layouts básicos gratuitos para download, instalação e personalização. Sendo destinado à equipes de desenvolvedores, grupos de trabalho dentre outros; apresentando uma sintaxe simples e poderosa que garante que os arquivos de dados sejam legíveis fora do Wiki (modelo específico de software para a criação de documentos em hipertexto) e facilita a criação de textos estruturados. 
Para disponibilizar a página do Biowiki na internet, primeiro foi necessária a escolha de um servidor web para hospedá-la. Por questões didáticas foi criada uma máquina virtual para simular esse processo e realizar-se a aplicação de testes e modificação do layout do template escolhido. A Figura 1 exemplifica o processo [18].

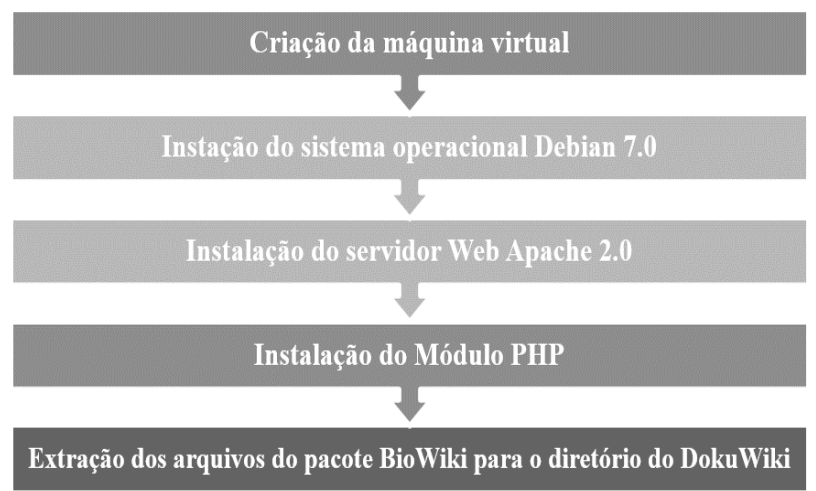

Figura 1: Processo de simulação da criação do servidor do BioWiki. Fonte: Autores

O site, em um primeiro momento, foi alocado em um servidor virtual da Amazon com um sistema operacional do tipo Linux, mais especificamente o Ubuntu 12.04 LTS. Esse servidor é acessado remotamente através de um sof- tware (SSH - Secure Shell), ou seja, a máquina física encontra-se geograficamente distante. A máquina servidora possui a seguinte configuração: 590MB de memória RAM, HD de 8GB, processador Intel Xeon E5645 com $2.4 \mathrm{GHz}$ de clock.

No decorrer do ano de 2015, foi realizada uma migração para o servidor GoDaddy e a compra do domínio definitivo do site BioWiki (www.biowiki.com.br). Dessa maneira, obteve-se a facilitação do acesso ao site, através do uso do CPanel - ferramenta de interface de usuário para controle do ambiente de hospedagem online - e o incremento da segurança do site.

No que se diz respeito à organização e disposição dos verberes na página web, torna-se imprescindível alguns comentários, uma vez que o dicionário está organizado de acordo com os assuntos trabalhados no ensino médio de forma didática e de fácil visualização e aquisição dos conceitos.

À medida que os verbetes forem sendo selecionados (pois estes estarão contidos também em hiperlinks dentro dos textos para evitar sua repetição, havendo apenas um redirecionamento), seus conceitos, imagens, vídeos referentes a ele - como verbetes secundários - aparecem, como mostra a Figura 2.

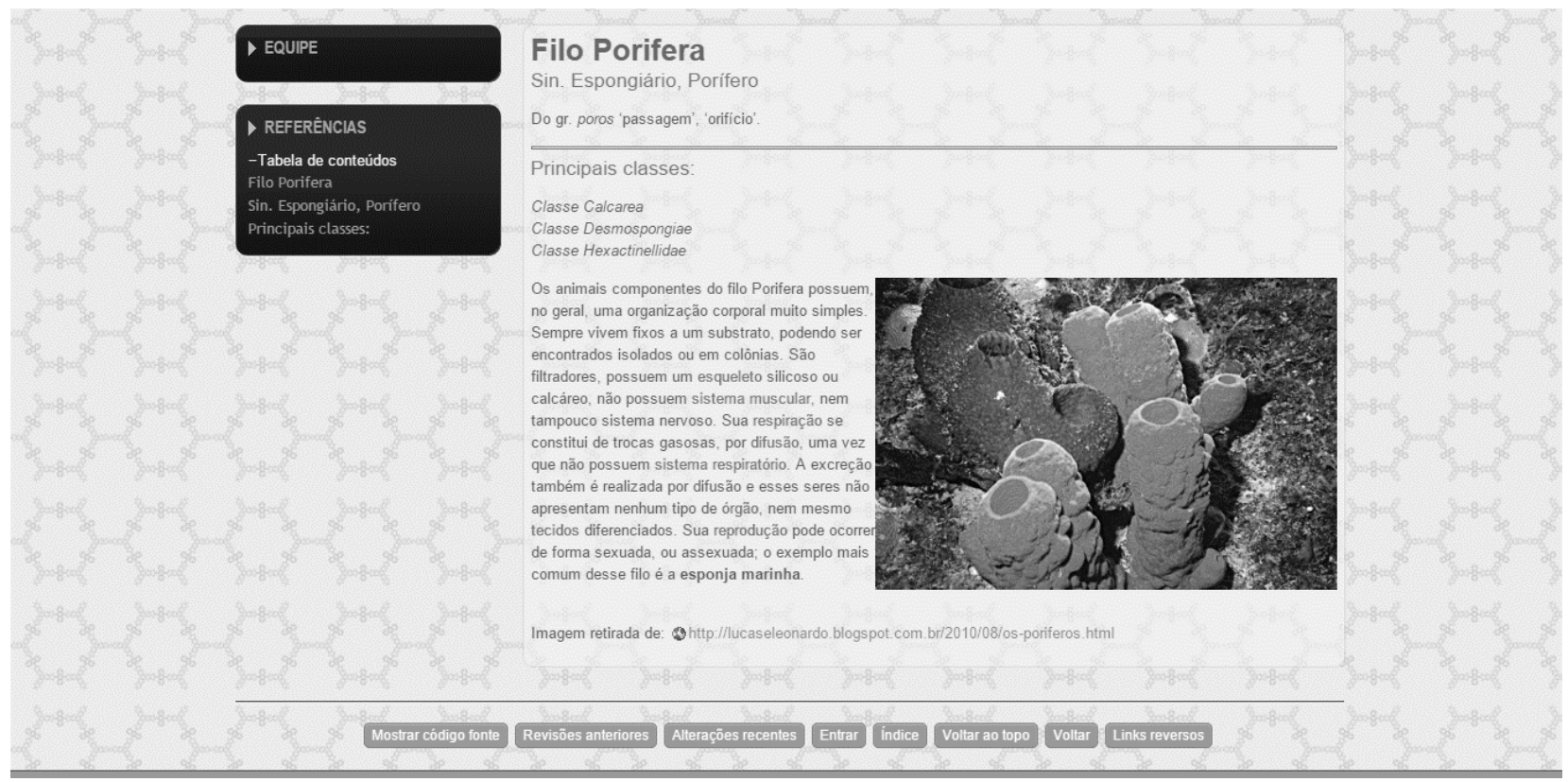

Figura 2: Exemplificação da disposição de um verbete no site. Fonte: autores

Decidiu-se dispor os verbetes no site por assunto, uma vez que existem divergências entre as grades curriculares e abordagens de determinados conteúdos podem mudar de acordo com as diversas instituições de ensino. Além disso, com base na organização desses conteúdos nos livros didáticos dos autores trabalhados na proposta, buscou-se realizar-se uma hibridização entre esses assuntos, procurando-se padrões que fossem seguidos nessas obras, 
como por exemplo, bioquímica celular estando sempre sendo abordado primordialmente em livros didáticos do primeiro ano do ensino médio.

A página do dicionário virtual dispõe de ícones que dão acesso direto às redes sociais para a difusão da informação, onde o usuário poderá compartilhar os conteúdos os quais está acessando, caracterizando assim o principal veículo de divulgação do Dicionário, facilitando o repasse de informações; estando também associado ao site Institucional do IFRN (Figura 3).

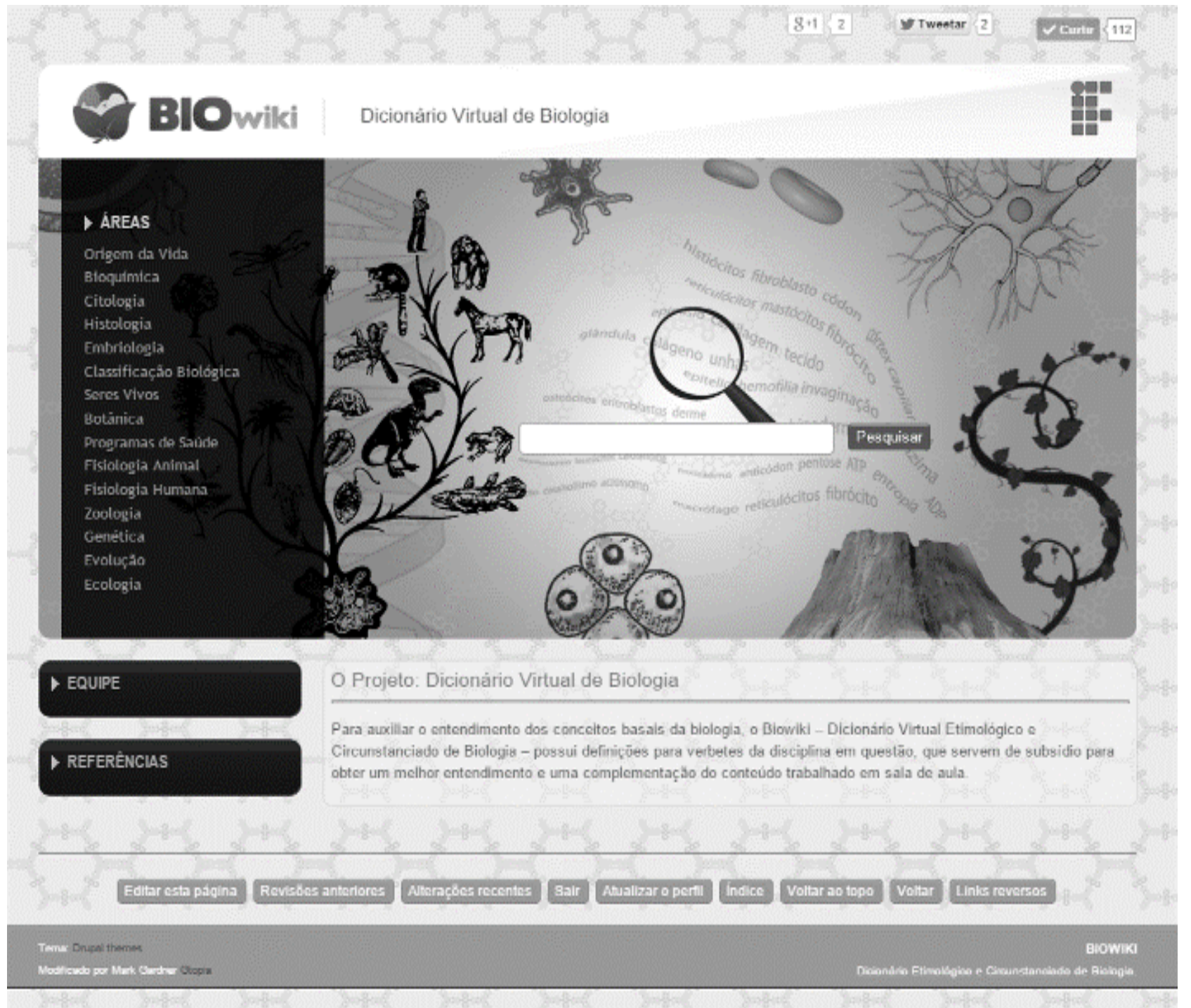

Figura 3: Página inicial do Dicionário Virtual de Biologia (www.biowiki.com.br). Fonte: autores.

Para configurar a praticidade da web existe um campo de busca no centro da página, que localiza o verbete no site e retorna links relacionados à procura realizada pelo usuário - Lídia Almeida Barros, em seu livro "Dicionários eletrônicos Aurélio e Houaiss: recursos informáticos de que dispõe semelhanças e diferenças" [4], diz que as obras eletrônicas apresentam como principal vantagem a possibilidade de busca da informação por meio de chaves de acesso, sendo que a forma impressa não permite.
Cada palavra apresenta sua etimologia, além de outros recursos como imagens, animações, vídeos, gráficos, diagramas, fluxogramas, reações químicas, desenhos esquemático etc., sendo utilizados como ferramentas acessórias para explanar o conceito do verbete ou expressão biológica, obtendo, dessa forma, um aprofundamento conceitual e aquisição da aprendizagem do termo biológico a ser desenvolvido junto aos alunos em sala de aula. Nesse sentido, há um redirecionamento para material online confiável e já filtrado pela equipe gestora do site com citações das fontes de busca das informações. 
Além do processo de construção da página web para alocação dos conceitos biológicos estabelecidos, convém tratar-se da construção do aplicativo para smatphones Android, configurando-se a praticidade para acesso à informação para fins de acessibilidade.

A plataforma de desenvolvimento selecionada para aplicação foi o Android Studio, visto que ele possui mecanismos de uso mais simples que o tradicional Eclipse. Atrelado à esse processo, deve-se realizar o estudo dos conceitos básicos e necessários para se programar em Android, por meio do material do Metrópole Digital - curso técnico em programação web oferecido pela Universidade Federal do Rio Grande do Norte -, bem como dar início a prática de desenvolvimento da aplicação com o auxílio do livro "Android para Programadores" dos autores Paul Deitel, Abbey Deitel, Harvel Deitel e Michael Morgano, processo que deve se estender até o fim do ano de 2015.

\section{Discussão}

De acordo com o que já foi dito anteriormente, vivencia-se um momento no qual se rompeu com paradigma de que um dicionário é apenas um "conjunto de unidades lexicais identificadas, organizadas e codificadas" [10]. Conforme foi dito por Nunes [19]

“...a visão histórica que evocava um passado literário como modelo não se sustenta mais diante dos novos movimentos sociais. Com as mudanças conjunturais que levaram à legitimação de uma camada social em ascensão nos centros urbanos, novos instrumentos são fabricados visando a esses interlocutores."

Desta forma busca-se cada vez mais fazer a correspondência entre o público e o instrumento didático, "rompe-se com a perspectiva histórica e anuncia a descrição do uso" [19]. Essa situação é constatada a partir da instauração de novos meios de veiculação da informação.

Em 2005 foi publicado um estudo comparativo entre os dicionários eletrônicos Aurélio e Houaiss por Lídia Almeida Barros, intitulado de "Dicionários eletrônicos Aurélio e Houaiss: recursos informáticos de que dispõe semelhanças e diferenças". Nesse livro é explicitada a forma com a qual as ferramentas informáticas modernas transformaram o processo de criação, gestão, difusão e exploração dos dicionários.

Lídia Almeida Barros [4], em seu livro, diz que o meio eletrônico - nesse caso ressalta-se a utilização de dicionários que portam essa característica - tem conquistado cada vez mais espaço entre os leitores por inúmeras razões, dentre as quais se destacam a interatividade e recursos multimídia.

\begin{abstract}
"As obras de consulta multimídia podem ser usadas para obter informação de formas que seriam impensáveis com os livros impressos. Não só é possível incorporar animações, vídeos, som, fala e texto, para ressaltar a apresentação da informação escrita, como ainda recorrer ao hipertexto e a hotspots que permitem ao utilizador procurar informações específicas ou aprofundar um tema. Tal como pode mudar de pista quando ouve um CD áudio, pode também saltar de um assunto para outro CD-Rom [4]."
\end{abstract}

Posto isso, cabe aqui então trazer-se breves conceitos que auxiliarão no entendimento do princípio de funcionamento/arquitetura da proposta. O primeiro a tratar-se é o conceito de hipertexto, o qual está contido no Dicionário Houaiss eletrônico [9]. Por hipertexto compreende-se, em Editoração e Informática, uma forma específica de apresentação de informações em um monitor de vídeo, na qual algum elemento (por exemplo, palavra, expressão ou imagem) é destacado e, quando acionado provoca a exibição de um novo hipertexto com informações relativas ao referido elemento.

Uma referência dentro de um documento em hipertexto - que geralmente aparece destacada - a outras partes desse documento é denominada de hiperlink. Esse mecanismo possibilita o leitor a escolher a sequência de sua leitura, bem como o quê e quando ler. Consecutivamente, um link é a forma reduzida de um hiperlink, sendo considerada a ligação entre as palavras, textos e outros; podendo este levar a uma imagem, a um texto, som, vídeo, outro documento ou mesmo outro protocolo, através do seu endereço na Web. A praticidade desse hábito e a interatividade da página atribuem a esse maior autonomia na construção de uma rotina de aprendizado que se molde a seus hábitos, e consequentemente mais opções e liberdade de escolha na obtenção das informações [9].

A partir de associações desses elementos da informática, surgem novos elementos mais abrangentes, como por exemplo, da associação de hipertexto com os recursos multimídia originou-se o conceito de hipermídia, ou seja, "conjunto de informações apresentadas na forma de textos, gráficos, sons, vídeos e outros tipos de dados, e organizadas segundo o modelo associativo e de remissões, próprio do hipertexto" [8].

Dentro desse contexto, em uma cadeia de novos conceitos que se criam com o desenvolver da tecnologia e de suas aplicações didático científico, surge o hiperdocumento, que se refere a um arquivo que apresenta recursos hipermídia em formatos diversos - como diagramas, textos, imagens, sons, softwares interligados aos documentos por meio de links programados em pontos chaves, de modo 
que o usuário possa passar de uma informação para outra, conforme seu interesse [9].

"Esses "links programados em pontos chaves" são chamados, em Informática hotspots, isto é, pontos quentes ou áreas sensíveis. Um hotspot é um botão ou imagem que reage quando selecionado, conduzindo-nos, por exemplo, a outro ponto da obra. Os hotspots podem ser invisíveis e apenas darmos por eles quando exploramos a tela do computador e notamos que o ponteiro (em geral, uma seta) muda de forma. O hot text ("texto quente"), ao pé da letra, é uma palavra ou frase que aparece numa cor diferente da do texto principal [4]."

Hotspots, hot texts ou hotwords são, assim, elementos constituídos de links que permitem rápidas consultas e a escolha de múltiplos percursos de navegação.

Associando a gama de recursos disponibilizados por esse modelo de ferramenta educacional o leitor tem, por exemplo, através do hipertexto, a possibilidade de decorrer e selecionar os conceitos que compõem sua nomenclatura, encontrando muito rapidamente as informações que deseja, ultrapassando obstáculos que a versão impressa (em papel) da obra imporia, corroborando a praticidade fornecida por esse instrumento.

Assim, pode-se considerar, pois, que a última geração, no que concerne aos dicionários, é composta pelos dicionários digitais multimídia, os quais se encontram, ainda, avançando concomitantemente à evolução das tecnologias na área de informática e da área tecnológica em geral. De forma que busca-se um progresso nos recursos disponibilizados por esse tipo de obra, fazendo com que o áudio permita, além do treinamento de pronúncia por parte do usuário, a reprodução de cantos de pássaros, vozes de animais, sons de instrumentos musicais e outros.

Dessa forma, a adaptação desses instrumentos didáticos aos moldes contemporâneos se tipifica como um forte argumento para que esse modelo de ensino seja adotado, pois os dicionários de referência da Língua Portuguesa estão sendo adaptados às novas didáticas de ensino para corroborarem como ferramentas exponencialmente mais poderosas no contexto da evolução das práticas educacionais.

Segundo Barros [4] a Língua Portuguesa se beneficiou com o lançamento do formato eletrônico de duas grandes obras lexicográficas: Dicionário Aurélio da Língua Portuguesa e O Grande dicionário Houaiss da Língua Portuguesa. Assim, pois, o acesso à informação desses dois livros torna-se de certa forma módico.
Além disso, um acontecimento que também tende a contribuir com esse cenário é a disponibilidade online do Vocabulario Portuguez e Latino (1712), escrito pelo padre inglês Raphael Bluteau (1638-1734), considerado como primeiro dicionário da Língua Portuguesa, o qual foi inteiramente digitalizado por alunos e docentes do Instituto de Estudos Brasileiros (IEB) da Universidade de São Paulo (USP).

O surgimento de novas ferramentas, bem como o de novos espaços para o ensino, está intimamente ligado à internet, a qual se caracteriza como um recurso de aprendizado simultâneo. Essa se tornou um meio propulsor para a ampliação e formação de novos espaços e de novas formas de atuação no mundo contemporâneo - sua aplicação é tão vasta, que dificilmente conseguir-se-ia relatar todas elas.

O processo de ensino aprendizagem através de novos espaços tem se expandido na última década, devido à utilização do espaço virtual da internet para fins educacionais, como supracitado. A expressão "espaço de aprendizagem" indica, na sua aplicação tradicional, "sala de aula, biblioteca, laboratório...", onde é possível mensurar e localizar os objetos que o compõem. Porém, os "novos espaços de aprendizagem" apresentam uma conotação diferenciada da que descrevemos. As dimensões destes espaços são imaginárias e os objetos não são reais, mas sim virtuais [7].

Diante desse cenário, considera-se o espaço de aprendizagem virtual como um local não situado geograficamente, onde ocorre o processo de ensino e de aprendizagem através da organização e aplicação de uma estrutura pedagógica contendo comunicação e interação. Dessa maneira, obtém-se excelentes meios de aprendizado, os quais são amplamente utilizados atualmente.

Como já exposto anteriormente, o fato do estudante do ensino médio ter certa dificuldade na compreensão dos conceitos biológicos, devido a sua complexidade e a linguagem técnico-científica muitas vezes utilizada, remetese ao uso de um dicionário técnico biológico.

Essa metalinguagem presente na atmosfera de qualquer área do saber constrói um campo focado de visão, de modo que só é possível aprender uma ciência quando se adquire a competência linguística do seu universo de discurso [3]. Portanto, é notório que os vocabulários técnico-científicos constituem um instrumento de trabalho indispensável e imprescindível ao estudante. Nesse contexto, o desenvolvimento de ferramentas que permitam estabelecer relações entre termos e seus conceitos revela-se eficaz para a compreensão a comunicação.

Então, com base no que se acredita ser um dos pilares para a boa formação do estudante - o alcance do conhecimento científico - a elaboração de um dicionário online pretende colaborar como um apoio didático e pedagógico 
para o processo ensino-aprendizagem da Biologia, podendo especializar-se em melhorar a percepção da relevância do estudo desta disciplina por parte do aluno, ou seja: da compreensão de fatos cotidianos. Por exemplo, entender doenças e mecanismos de cura, efeito estufa e temas como remediação, ecologia, diversidade dos seres vivos, entre outros, só são passíveis de compreensão através do estudo da Biologia. É perceptível, portanto, a presença desta disciplina no nosso dia-a-dia e a importância de estudá-la. Em decorrência disso faz-se necessária a compreensão de conceitos atrelados a esta disciplina sendo que, o acesso a essas informações se darão de forma ampla e fácil para maior compreensão do conteúdo.

Como já citado, há mais de 20 anos foi publicado, por José Luís Soares, um dicionário etimológico e circunstanciado de biologia, no qual já está presente a etimologia dos termos, além de circunstanciá-los dentro do contexto referente à área de estudo. Porém essa versão é impressa, o que acarreta numa série de complicações em se ter acesso às informações contidas nessa obra, além de ser antiga, o que demonstra uma necessidade em se fazer uma adequação dessas informações de acordo com a época vigente.

A carência de informações confiáveis na internet também é um ponto chave para o desenvolvimento deste material. A problemática é que, por ser capaz de permitir que qualquer pessoa crie sites sobre os mais diversos temas, as informações que circulam na rede acabam sendo prolixas e, muitas vezes, contraditórias, ou seja, nem sempre confiáveis [6].

Frente a isso, o desenvolvimento do Dicionário Biológico Etimológico e Circunstanciado Online - Biowiki (Figura 3) minimizará esse conflito de informações por meio da condensação dos conceitos e abordagem em linguagem adaptada ao público-alvo, num ambiente propício de difusão de informações e conhecimento (a internet). Tendo em vista também que os conceitos não são unidades isoladas, mas ao contrário, são relacionadas a outros e compartilham algumas características, entre a conceituação dos verbetes apresentando links que redirecionam o aluno a outras definições complementares dentro da própria página - o que torna a pesquisa mais dinâmica e de fácil compreensão.

Presentemente leva-se muito em consideração a qualidade das informações fornecidas ao estudante e a forma com a qual essa informação é transmitida. Ou seja, trazer apenas o conceito, sem informações pertinentes à sua utilização pode chegar a confundir o estudante. "A opinião pode até ser válida em determinada situação, mas erroneamente é generalizada, ou seja, considerada correta em todas as situações de aprendizagem", explicita Welker [27].

Desta forma, atrelando-se o momento vigente à evolução das novas tecnologias, é urgente a necessidade de uma reestruturação das arcaicas estruturas de ensino, de modo a adaptá-las aos novos valores e conceitos adotados pelos estudiosos na atualidade. Deve-se levar em consideração que é vital torná-las atrativas para o público-alvo, no caso os discentes, se essa ótica for estendida para o ambiente da sala de aula. Sendo fundamental criar um ambiente que favoreça a aprendizagem significativa ao aluno, "desperte a disposição para aprender, disponibilizando as informações pertinentes de maneira organizada e, no momento apropriado, promovendo a interiorização de conceitos construídos" [1].

Vista essa situação, é urgente a realização de investimentos em novas formas de difusão e fornecimento de informações credenciadas aos jovens - não só a eles, bem como a toda comunidade -, que portem qualidade e sejam simplificadas, para que esse possa naturalmente fazer uso de certo meio para subsidiar seu conhecimento, sem demais complicações.

\section{Conclusão}

Observa-se que ao trazer o conceito de biologia de uma forma simplificada, além de explaná-lo por meio de imagens, vídeos, gráficos e esquemas, tem-se uma melhor fixação dos vocábulos pelo aluno, melhorando sua compreensão do conteúdo de biologia aplicado no ensino propedêutico. Portanto, é incontestável a importância do dicionário virtual, etimológico e circunstanciado proposto nesse trabalho. Ele, bem como os livros didáticos convencionais, torna-se um instrumento essencial na armazenagem e recuperação de fatos científicos, além de ser um importante instrumento de pesquisa e de sustentação da estrutura teórica de uma ciência [11].

Tendo em vista que a construção da página foi finalizada e visto que a biologia não é uma ciência exata, sua manutenção é feita com base na análise das dificuldades dos estudantes na compreensão de determinado conceito e discussões contemporâneas no âmbito didático pedagógico inerente à disciplina; ou seja, novas funcionalidades e informações serão acrescidas gradualmente ao site mediante o surgimento de novas demandas. Além de que a dinâmica do ambiente virtual obriga o usuário a se atualizar constantemente, de forma que a página, com o passar do tempo, necessita de uma manutenção e melhoria, pois o cerne da proposta diz respeito à oferta de informações atuais e confiáveis.

Visa-se, a oferta de uma ferramenta que auxilie os estudantes dessa disciplina, um retorno positivo à comunidade escolar promovendo uma melhor fixação do conteúdo pelo aluno e o aperfeiçoamento de sua sabedoria. Nesse sentido, espera-se que este recurso sirva como complemento aos livros didáticos convencionais, sendo um instrumento essencial na armazenagem e recuperação de dados científicos e que convenha como um ótimo mecanismo de pesquisa. 
Contudo, levanta-se aqui uma problemática relacionada à disponibilidade da internet ao usuário em determinadas situações, o que remete ao uso de uma tecnologia em ascensão: as aplicações para dispositivos móveis, as quais, em sua maioria, permitem o acesso a determinadas informações mesmo que o usuário não esteja conectado à internet, pois muitas vezes torna-se mais cômodo possuir uma aplicação off-line em dispositivo móvel, que sujeitar-se a fatores externos, bem como à disponibilidade de uma rede para conexão.

Então, com a finalização desta etapa de desenvolvimento do projeto, coloca-se como abordagem complementar a implementação de um aplicativo para dispositivos móveis, desenvolvida na plataforma Android, amplamente difundida e popular, que contenha um banco de dados com o registro de todos os verbetes cadastrados no site, podendo esses serem acessados quando o usuário não estiver online, mediante a instalação prévia da aplicação.

Atrelado a essa, pensando-se em conquistarem-se novos horizontes, é viável que, por meio do auxílio de ferramentas informacionais mais modernas, realize-se uma adaptação da página para outro idioma, nesse tocante a língua inglesa.

Assim, ter-se-á, além das funções basais características de um dicionário, a construção de um ambiente permissivo não apenas à consulta, mas também ao estudo, à formulação e ao compartilhamento de conhecimentos. Para alcançar tal intento, tem-se a implementação de uma interface que privilegia a interação com o usuário, fornecendo ferramentas para o desenvolvimento e o compartilhamento de esquemas, conceitos, gráficos e tabelas, como também recursos como animações e vídeos biológicos. Dessa forma, espera-se a formação de uma rede de estudos baseada na estrutura clássica de um dicionário, porém com a disponibilidade de recursos modernos facilitadores do processo de ensino-aprendizagem.

\section{Referências}

[1] M. E. B. Almeida. Educação a distância na internet: abordagens e contribuições dos ambientes digitais de aprendizagem. Educação e Pesquisa, São Paulo, v.29, n.2, p. 327-340, jul./dez. 2003.

[2] J. M. Amabis, ,G. R. Martho. Biologia das células: origem da vida, citologia e histologia, reprodução e desenvolvimento. 2. ed. São Paulo: Moderna, 2004.
[3] M. A. Barbosa. Transposições vocabulares e terminológicas em campos lexicais - ensino da metalinguagem técnico-científica. In: VI Congresso Nacional de Lingüistica e Filologia - Cadernos do CNLF, Série VI, no.07_ Léxico - Semântica e Lexicologia. Rio de janeiro, RJ. 2002.

[4] L. A. Barros. Dicionários eletrônicos Aurélio e Houaiss: recursos informáticos de que dispõe semelhanças e diferenças - São Paulo; Annablume; Fapesp, 2005.

[5] M. T. C. Biderman. Dicionários do português: da tradição á contemporaneidade. Programa de PósGraduação em Linguística e Língua Portuguesa Faculdade de Ciências e Letras - UNESP - 14800901 - Araraquara - SP - UNESP. Alfa, São Paulo, 47(1): 53-69, 2003.

[6] R. C. F. Castro. Impacto da Internet no fluxo da comunicação científica em saúde. Rev Saúde Pública 2006;40 (N Esp):57-63. Disponível em: $<$ http://www.imeo.com.br/artigos/internet.pdf $>$ Acesso em: 26 jun 2012.

[7] L. S. Comasseto. Novos espaços para o ensino e a aprendizagem em EAD. Universidade do Contestado - UnC, 2007. In: $13^{\circ}$ Congresso de Educação a Distância, Curitiba, PR. 2007.

[8] Dicionário Aurélio Eletrônico; século XXI. Rio de Janeiro, Nova Fronteira e Lexicon Informática, 1999, CD-rom, versão 3.0 .

[9] Dicionário Houaiss Eletrônico Da Língua Portuguesa. Rio de Janeiro, Objetiva, 2001, CD-rom versão 1.0 , para Windows.

[10] Dicionário Priberam Da Língua Portuguesa. Disponível em: <http://www.priberam.pt/dlpo/> Acesso em: 23 Set 2013.

[11] V. Duarte. Uso do dicionário no início da escolaridade: Os benefícios obtidos por meio do uso do dicionário desde o início da escolaridade são indiscutíveis, sobretudo no aprimoramento da competência linguística dos educandos. Disponível em: $<$ http://educador.brasilescola.com/estrategias-ensino/uso-dicionario-no-inicio-escolaridade.htm> Acesso em: 07 Jul 2013.

[12] M. Ferrari. Aristóteles: o primeiro lógico via na escola o caminho para a vida pública e o exercício da ética. Disponível em: <http://educarparacrescer.abril.com.br/aprendizagem/aristoteles307025.shtml> Acesso em: 05 Jul 2013. 
[13] P. V. N. Gomes. O processo de aquisição lexical na infância e a metalexocografia do dicionário escolar. Universidade de Brasília, Instituto de Letras - Brasília, 2007.

[14] Eleanor. Lawrence. Henderson's Dictionary of Biological Terms. Editora: Prentice Hall. England. Twelfth Edition, 2000.

[15] O. Lessa. Dicionário Básico de Biologia. Editora Ciência Moderna, 2007.

[16] S. G. B. C. Lopes. Bio: volume único. São Paulo: Saraiva, 1994.

[17] S. Machado. Biologia: volume único para o ensino médio. 1. ed. São Paulo: Scipione, 2006.

[18] C. E. Morimoto. Redes e servidores Linux: guia prático. 2.ed. Porto Alegre: Sul Editores, 2006.

[19] J. H. Nunes. Dicionário, sociedade e língua nacional: o surgimento dos dicionários monolíngues no Brasil. Cores, marcas e falas. Sentidos de mestiçagem no Império do Brasil. Rio de Janeiro, 2008.

[20] E. Oliveira. Da pedra ao LCD: a evolução(?) dos dicionários. Disponível em: $<$ http://www.portaleducacao.com.br/idiomas/artigos/22997/da-pedraao-lcd-a-evolucao-dos-dicionarios\#ixzz2dDY5bAtG> Acesso em: 08 Jul 2013.

[21] E. O. Rangel, M. Bagno. Dicionários em sala de aula, 1 ed. Brasília: Ministério da Educação, Secretaria de Educação Básica, 2006. 155p.

[22] C. S. JÚNIOR, S. SASSON. Biologia 1. 7. ed. São Paulo: Saraiva, 2007.

[23] J. L. Soares. Dicionário Etimológico e Circunstanciado de Biologia. São Paulo: Scipione, 1993.

[24] A. M. Sousa. O uso do dicionário em sala de aula. In: III Jornada Nacional de Linguística e Filologia da Língua Portuguesa, Acre: UFAC, 2008.

[25] A. Uzunian, E. Birner. Biologia: volume único. 2. ed. São Paulo: Harbra, c2004.

[26] I. Vázquez. O papel do dicionário no ensino e aprendizagem das Línguas. Universitat de Barcelona, Março/2010.

[27] H. A. Welker. Sobre o uso de dicionários. In: VIII Encontro do CELSUL, Brasília, 2008. Anais do CELSUL 2008, Porto Alegre: UFRGS. 